DECLARACIÓN DE GOBIERNO DEL MINISTRO

FEDERAL DE RELACIONES EXTERIORES, SR. HANSDIETRICH GENSCHER, EN RELACIÓN CON EL TRATADO SOBRE EL ACUERDO DEFINITIVO CON RESPECTO A ALEMANIA ANTE EL BUNDESTAG ALEMÁN EL 20 DE SEPTIEMBRE DE 1990 
Revista de Derecho Político, núm. 40, 1995, pp. 313-327

\section{DECLARACIÓN DE GOBIERNO DEL MINISTRO FEDERAL DE RELACIONES EXTERIORES, SR. HANS-DIETRICH GENSCHER, EN RELACIÓN CON EL TRATADO SOBRE EL ACUERDO DEFINITIVO CON RESPECTO A ALEMANIA ANTE EL BUNDESTAG ALEMÁN EL 20 DE SEPTIEMBRE DE 1990}

Señora Presidenta, señoras y señores:

El pasado 12 de septiembre se firmó en Moscú el Tratado sobre el acuerdo definitivo con respecto a Alemania. Este tratado y el tratado de unificación, cuyo debate parlamentario concluimos hoy, nos abre a los alemanes la vía hacia la unificación en libertad.

La firma del documento definitivo constituye el punto final de la historia de la posguerra europea. A los alemanes nos brinda una nueva oportunidad. A Europa se le presenta la posibilidad de iniciar en términos globales una nueva singladura.

El tratado apunta hacia un futuro europeo más venturoso. Es un documento que atestigua la voluntad de paz de todos los implicados.

Con este tratado las Cuatro Potencias ponen fin a sus derechos y responsabilidades con respecto a Berlin y Alemania en su conjunto. Con la entrada en vigor del tratado, la Alemania unida alcanzará la plena soberanía sobre sus asuntos internos y exteriores. Esto incluye el derecho de pertenecer a alianzas con todos los derechos y obligaciones que de ello se derivan. Hemos alcanzado nuestro objetivo de no lastrar a la Alemania unida con cuestiones pendientes.

El 1 de octubre de 1990 está previsto firmar en Nueva York un documento por el cual se suspendan los derechos y responsabilidades de las Cuatro Potencias desde el día de la unificación hasta la entrada en vigor del tratado.

El tratado sobre el acuerdo definitivo lleva todavía la firma de los representantes de ambos Estados alemanes, pero su ratificación corres- 
ponderá ya al primer Parlamento alemán común, que se constituirá después del 3 de octubre de 1990.

Vamos a someter los resultados de las conversaciones "Dos más Cuatro" primero a la conferencia de Ministros de Relaciones Exteriores de los países participantes en la CSCE los días 1 y 2 de octubre en Nueva York, y a continuación en otoño, de forma solemne, a la cumbre de la CSCE.

Los países participantes en la CSCE reconocen ya en estos momentos que el establecimiento de la unidad estatal de Alemania no crea nuevos problemas para Europa, sino que antes bien fortalece la esperanza de un futuro mejor para Europa. En el tratado sobre el acuerdo definitivo con respecto a Alemania los alemanes asumimos la responsabilidad que le incumbe a la Alemania unida en relación con la paz.

Reafirmamos de forma solemne que de suelo alemán sólo emanará la paz. Hacemos constar que los actos susceptibles de perturbar las relaciones pacíficas entre las naciones y realizados con tal intención, especialmente para preparar una guerra de agresión, son anticonstitucionales y punibles.

Proclamamos ante todo el mundo que jamás emplearemos nuestras armas, excepto en concordancia con nuestra Constitución y la Carta de las Naciones Unidas.

La política de la Alemania unida será una política de predicar con el ejemplo: animados de este espíritu, reafirmamos nuestra renuncia a la fabricación, posesión y control de armas nucleares, biológicas y químicas. Reafirmamos la vigencia de los derechos y obligaciones derivados del Tratado sobre la no proliferación de armas nucleares. Nuestra decisión de reducir en un plazo de tres a cuatro años los efectivos de la Alemania unida a $\mathbf{3 7 0 . 0 0 0}$ hombres es un significativo aporte alemán a la reducción de las fuerzas armadas convencionales en Europa. Esperamos que cunda el ejemplo.

El próximo 3 de octubre el pueblo alemán volverá a vivir en su conjunto en un Estado democrático - por primera vez desde hace 57 años- La perspectiva de esta fecha nos llena de satisfacción y gratitud y es motivo de reflexión.

Después del 30 de enero de 1933, fecha en que la noche del fascismo cayó sobre Alemania, perdimos primero nuestra libertad y nuestra paz interna. Perdimos la paz externa y perdimos nuestra unidad estatal. Muchos alemanes perdieron la vida, la salud, la fortuna y la patria. $Y$ to- 
dos nosotros perdimos el respeto y la amistad de los otros pueblos. Todo eso empezó el 30 de enero de 1933. Conscientes de la anuencia de las Cuatro Potencias en relación con la unión estatal de los alemanes, recordamos el infinito sufrimiento infligido a los pueblos en nombre de Alemania. Recordamos a todas las víctimas de la guerra y de la tiranía. Nos unimos con la voluntad de que aquello no se repita nunca más. Nuestros pensamientos se dirigen especialmente al pueblo judio. También la Alemania unida es consciente de su especial responsabilidad frente al pueblo judio.

Al celebrar hoy aquí la firma del Tratado sobre el acuerdo definitivo con respecto a Alemania sentimos que la comunidad internacional nos acompaña en la senda hacia la unidad estatal, honrándonos con su confianza.

Gracias a la construcción de un orden estatal y social liberal en la República Federal de Alemania y a la política de paz y responsabilidad de nuestro Estado, las naciones han vuelto a depositar su confianza en nosotros.

La pacífica revolución por la libertad en la RDA ha convencido a los pueblos del mundo de que los alemanes están aprovechando la oportunidad que brinda la libertad para vivir en paz y libertad.

El mundo ha reconocido que los alemanes apostamos por la fuerza pacificadora de los derechos humanos y de la dignidad humana, de la libertad y la democracia. Largo ha sido el camino que nos ha llevado desde los escombros de la Segunda Guerra Mundial hasta donde hoy nos encontramos. En esta etapa surgió el ordenamiento estatal y social más liberal y social de nuestra historia. En cuanto a la política exterior, los principales hitos en esta senda han sido las incorporaciones al Consejo de Europa, a la Alianza Occidental y a la Comunidad Europea. Con estos pasos regresamos a la comunidad de las democracias.

Los Tratados de Moscú y Varsovia, el Tratado con la República Federal Checa y Eslovaca y el Tratado sobre las bases de las relaciones entre la República Federal de Alemania y la República Democrática Alemana sentaron las bases de unas nuevas relaciones con nuestros vecinos del Este y regularon las relaciones entre los dos Estados alemanes durante la etapa de división estatal. Los nombres de Konrad Adenauer, Willy Brandt y Walter Scheel ilustran las decisiones fundamentales de la política exterior alemana de la posguerra. La política de tratados de la República Federal de Alemania dio paso asimismo al Acta Final de Helsinki. Sobre la base del Tratado de Moscú, la declaración germano-soviética del 13 de junio de 1989 dio nueva entidad a las relaciones germano-soviéti- 
cas. Fue un importante paso hacia el tratado general rubricado el 13 de septiembre de 1990 en Moscú.

La unificación alemana nos brinda a los alemanes la histórica oportunidad de contribuir de consuno a una Europa pacifica, libre y unida. En la senda europea de los alemanes hacia su unidad estatal culmina lo que quedó establecido en el preámbulo de nuestra Ley Fundamental. Se hace realidad lo que Francia, los Estados Unidos de América y el Reino Unido de Gran Bretaña e Irlanda del Norte suscribieron en los acuerdos de Bonn del año 1954.

Se cumple lo que reafirmamos como objetivo de nuestra política de paz europea en la Carta sobre la unidad alemana con ocasión de la concertación del Tratado de Moscú. Vamos a ejercer nuestra plena soberanía de acuerdo con nuestra responsabilidad por la paz europea. La Alemania soberana, democrática y liberal ha abrazado la causa de la unidad, la estabilidad y el progreso de Europa en su conjunto.

También queremos contribuir a que Europa esté en condiciones de hacer frente a su responsabilidad con vistas a la configuración de un nuevo orden internacional.

La Alemania unida tendrá mayor peso. Sabemos que los pueblos de Europa se plantean la pregunta de cómo vamos a aprovechar ese peso los alemanes. La respuesta es clara: con ese mayor peso no aspiramos a tener más poder, sino que, antes bien, somos plenamente conscientes de la mayor responsabilidad que ello entraña.

La política de la Alemania unida se guiará por el deber de paz y por los valores fundamentales de nuestra Constitución.

Recordamos con respeto y gratitud la amplitud de miras y la prudencia de las mujeres y los hombres que concibieron nuestra Ley Fundamental. Incluso tomando como base las experiencias de cuatro décadas de política alemana de posguerra, hoy en día nuestro mandato no podría formularse más atinadamente que el mandato constitucional contenido en el preámbulo de nuestra Ley Fundamental: consumar la unidad de Alemania, unir a Europa y servir a la paz del mundo. En ello estriba la vocación europea de los alemanes y su responsabilidad por la paz.

El destino alemán se enmarca en el destino de Europa. Siempre fuimos conscientes de que a la escisión de Alemania sólo podría ponérsele fin si se superaba la división de Europa. Por eso no dejamos de abogar por la unidad de las democracias europeas, por eso asumimos nuestra responsabilidad en la Alianza Atlántica. 
Trabajamos infatigablemente en pro de la superación del antagonismo Este-Oeste. Una y otra vez dimos nuevos impulsos al proceso CSCE, aprovechamos todas las oportunidades que se nos presentaron en orden al desarme y no dejamos de propiciar una inflexión en las relaciones entre los miembros de las dos Alianzas.

Todos estos esfuerzos, que culminaron en la capital mejora de nuestras relaciones con la Unión Soviética, modelaron a la postre las condiciones marco bajo las cuales se pudieron concluir al cabo de pocos meses las conversaciones "Dos más Cuatro" acordadas el 13 de febrero de 1990 en Ottawa. Vamos a llevar adelante nuestra política, asentada en el compromiso europeísta.

Queremos que la Comunidad Europea se convierta en Unión Europea, que abarque tanto la Unión Política como la Unión Económica y Monetaria. Cuanto antes alcancemos la Unión Europea, más potenciaremos la unidad de Europa en su conjunto. La Comunidad Europea es un elemento capital de la futura Europa cabal. A partir del 3 de octubre de 1990 también se incorporarán a la Comunidad Europea los nuevos Estados Federados. Hemos de agradecer a las instituciones de las Comunidades Europeas, y muy especialmente al Presidente de la Comisión, Jacques Delors, que hayan preparado y posibilitado con gran empeño las decisiones necesarias al efecto.

La singular vinculación entre Alemania y Francia es sustancial para el futuro de la Comunidad Europea. A partir del 3 de octubre de 1990 todos los alemanes quedarán incluidos en esta vinculación. Propugnamos una cooperación franco-alemana cada vez más estrecha, como base de la política exterior alemana. El pasado 18 de septiembre el Canciller Federal Kohl y el Presidente Mitterrand hicieron la siguiente declaración conjunta: "La culminación de la unidad alemana, de la cual nos congratulamos, confiere un nuevo alcance y una mayor proyección a nuestra cooperación, que desde un principio se marcó como objetivo impulsar de consuno la integración europea en todos los campos".

Mayor responsabilidad significa asumir nuestro especial compromiso en relación con la evolución en Europa central y oriental.

Ahora que se han derribado los muros de los antagonismos ideológicos y los muros de piedra, no queremos que Europa siga estando dividida por el muro de un desarrollo económico divergente y de disparidades sociales. No vamos a olvidar la unidad de Europa en su conjunto por la unidad de los alemanes. Queremos una Europa solidaria y compenetrada, que haga realidad las expectativas de futuro de todos los pueblos europeos. Sólo podremos evitar un rebrote del nacionalismo si to- 
dos los países europeos toman la senda hacia Europa. El espiritu de la integración de Europa en su conjunto debe inspirarse en la nueva cultura de la convivencia de los pueblos de la Comunidad Europea. Nuestro objetivo sigue siendo el orden de paz europeo al que ya se refería nuestra alianza en el Informe Harmel de 1967.

Nuestro aporte a la Europa cabal es a la vez una inversión en nuestro futuro europeo.

La gren tarea de una política europea consagrada a la estabilidad, en la que los factores militares desempeñen un papel cada vez menos importante, estriba en crear unas sólidas condiciones marco a nivel político, económico, social y ecológico para los procesos de transformación en los paises de Europa central y oriental.

Por nuestro peso económico y político y por nuestra situación en el corazón de Europa, nos incumbe una especial responsabilidad al respecto.

En este orden de cosas, somos plenamente conscientes de que la Unión Soviética pertenece a Europa y de que sin su concurso no puede surgir la Europa cabal.

EI "Tratado de buena vecindad, amistad y cooperación" rubricado en Moscú está consagrado a esta gran meta europea. El tratado en cuestión no sólo sienta de cara al futuro unas nuevas bases para las relaciones germano-soviéticas, sino que a la par responde a la capital significación que revisten estas relaciones para Europa en su conjunto. Esta significación volvió a ponerse de manifiesto con ocasión del encuentro entre el Canciller Federal y el Presidente Gorbachov el pasado mes de julio en el Cáucaso. Queremos que esta nueva relación incluya también a los habitantes de nuestros dos países. Lo mismo vale también para los soldados soviéticos, que abandonarán durante los próximos tres a cuatro años el territorio de la actual RDA.

Ambos Estados están emprendiendo innovaciones con proyección europea global. Esto no se dirige contra otros ni priva a nadie de nada, sino que aporta una estabilidad adicional a Europa.

El tratado antedicho, al marcar nuevas pautas, atestigua que ambos Estados se toman en serio su propósito de forjar conjuntamente el futuro. Queremos que la confianza presida nuestras relaciones a todos los niveles. El Tratado sienta las bases al efecto. 
Se nos brinda la gran oportunidad de articular una cooperación amplia, estrecha y orientada hacia el futuro. Esta cooperación no es únicamente un asunto germano-soviético. A través de una estrecha cooperación con Alemania, que es miembro de la Comunidad Europea, está firmemente anclada en la Alianza Atlántica y se cuenta entre los motores del proceso CSCE, la Unión Soviética asocia su futuro a los destinos de Europa.

También con respecto a nuestras relaciones con Polonia reconocemos nuestra mayor responsabilidad por el futuro de Europa.

La inviolabilidad de las fronteras constituye uno de los elementos esenciales del orden de paz europeo. El tratado del 12 de septiembre de 1990 confirma el carácter definitivo de las fronteras de la Alemania unida: la Alemania unida no tiene reivindicación territorial alguna contra otros Estados ni formulará ninguna en el futuro. La Alemania unida confirmará la actual frontera germano-polaca en un tratado vinculante a efectos jurídico-internacionales. Ello se hará en el plazo más breve posible a partir del establecimiento de la unidad alemana.

Para millones de alemanes que tuvieron que abandonar su suelo natal en dolorosas circunstancias, esta decisión supone un aporte especial y personal a la paz en Europa. Con el Tratado de Varsovia ya rompimos definitivamente el círculo vicioso de injusticias reciprocas, allanando así el camino hacia la reconciliación con el pueblo polaco. Nuestras relaciones con Polonia patentizan particularmente nuestra vocación europea.

Por eso queremos sentar, en un tratado germano-polaco adicional de alcance general, las bases para abrir un nuevo capítulo de buena vecindad germano-polaca.

También vamos a asumir una mayor responsabilidad en la profundización e institucionalización del proceso CSCE. He aquí la gran tarea constructiva europea de la próxima década.

Hace 15 años, los 35 Estados firmantes del Acta final de la CSCE en Helsinki se obligaron a defender la libertad, la democracia y el respeto de los derechos humanos. Lo acontecido de entonces a esta parte le ha dado la razón a la audaz decisión de 1975.

La cumbre del próximo 19 de noviembre en París le dará una nueva categoría al proceso CSCE y creará las primeras instituciones comunes de la nueva Europa cabal. La celebración de reuniones periódicas a nivel de Jefes de Estado y de Gobierno de Ministros de Relaciones Exte- 
riores y la creación de un centro para la prevención de conflictos y una secretaria serán los primeros y sólidos fundamentos de un orden de paz duradero y cooperativo en toda Europa.

De la "Conferencia sobre la Seguridad y la Cooperación en Europa" emana progresivamente, con nuestro concurso activo, una "estructura de cooperación, seguridad y estabilidad europea».

El final de la confrontación Este-Oeste y las nuevas relaciones entre los Estados miembros de los sistemas de alianzas allanan el camino para nuevas estructuras cooperativas en Europa -incluidas estructuras cooperativas de seguridad en las que nuestra Alianza, a la que también pertenecerá la Alemania unificada, tiene asignado un importante papel en orden a la estabilidad europea-. Los soldados de nuestras Fuerzas Armadas Federales conservan dentro de esta política de seguridad cooperativa, bajo circunstancias novedosas, su mandato de salvaguardar la paz. Los soldados de toda Alemania prestarán su servicio por la paz en libertad y democracia dentro de esas Fuerzas Armadas Federales. El pueblo alemán, siendo uno, tiene un ejército, aunque el status de los nuevos Estados Federados en cuanto a la política de seguridad sea de momento diferente. Esto significa asimismo que a partir del 3 de octubre los soldados de las Fuerzas Armadas Federales serán estacionados junto a soldados del Ejército Rojo. Queremos que esto dé lugar a un nuevo talante y una nueva confianza.

Un sistema de seguridad europeo de carácter cooperativo institucionalizado en el marco de la CSCE aporta elementos esenciales a un nuevo orden de paz europeo del Atlántico a los Urales.

A tal efecto, las negociaciones de desarme deben ponerse de nuevo a la altura de los procesos políticos, que les han tomado vertiginosamente la delantera. Nosotros vamos a darles nuevos impulsos. Mayor responsabilidad significa a nuestro entender un fortalecimiento de las relaciones transatlánticas. El Atlántico no debe ensancharse a medida que la Comunidad Europea vaya adquiriendo enjundia en la senda hacia la Unión Europea. Al contrario, los dos continentes deben aproximarse aún más. Una declaración transatlántica de la Comunidad Europea y las democracias norteamericanas dará una nueva entidad a esta trabazón. La iniciativa en orden a una tal declaración parte de nosotros; la enfocamos desde la óptica de la unidad alemana y europea. La Alianza Atlántica, que redefinió en la declaración de Londres del pasado 6 de junio sus pautas de cara al futuro y su cometido, vincula a los Estados Unidos de América y al Canadá con las nuevas estructuras de seguridad cooperativa en Europa. El inseparable enlace de los Estados Unidos y el Canadá con los destinos de Europa y su concurso en el proceso CSCE se ilustran visible- 
mente en el hecho de que la conferencia de Ministros de Relaciones Exteriores de la CSCE de los próximos días 1 y 2 de octubre se celebrará en suelo americano.

La superación del conflicto Este-Oeste permite divisar con nitidez las expectativas de un nuevo orden mundial. La división de Europa y el conflicto Este-Oeste absorbieron durante décadas nuestras energías. Ahora queremos dedicarlas de consuno a Europa y al mundo.

La Alemania unida estará abierta al mundo y cumplirá con su responsabilidad también a este nivel. Cuanto más liberal y tolerante, justo y social sea nuestro orden estatal y social, tanto más nos granjearemos la confianza de las naciones, tanto mejor haremos honor a los valores fundamentales de nuestra Constitución y al espíritu del levantamiento pacifico en la RDA. La liberalidad, tolerancia, justicia y responsabilidad social, la solidaridad y la fraternidad habrán de acrisolarse precisamente ahora, al hilo de la comunión de los alemanes.

La política de predicar con el ejemplo nos obliga a afrontar los desafíos globales. Se trata de conservar el entorno natural del hombre, se trata de comprender que la erradicación del hambre y la miseria en el Tercer Mundo es la tarea social primordial a escala mundial en las postrimerías de nuestro siglo.

Se trata de solventar los problemas de la conversión de economías de armamento en economías de paz. El mundo en que vivimos, siendo uno solo, requiere nuevas estructuras de cooperación y salvaguardia de la paz a nivel regional y global.

La Alemania unida entiende que todas estas tareas constituyen un reto especial. Los valores fundamentales de nuestra Constitución no sólo inspiran nuestro ordenamiento estatal interno, sino también nuestra convivencia con las demás naciones y nuestro proceder a escala mundial. El respeto de la inviolable dignidad humana es el patrón de nuestra política en el plano interno y externo. En las conversaciones «Dos más Cuatro" todas las partes consideraron más importante conseguir un éxito conjunto que afanarse por ventajas unilaterales. Este ejemplo nos hace acariciar la esperanza de una nueva cultura de la convivencia internacional. política.

Queremos que la Alemania unida contribuya a ello a través de su

En el umbral de la unidad alemana, los alemanes damos las gracias a nuestros amigos y aliados de Occidente que nos han allanado el ca- 
mino de retorno a la comunidad de los pueblos libres. Fueron firmes valedores de Berlín y de los alemanes en los tiempos buenos y en los tiempos malos. El puente aéreo con Berlín no se olvidará nunca. Damos las gracias al Presidente Bush, al Presidente Mitterrand y a la Primera Ministra Thatcher, sin cuyo respaldo y comprensión por las aspiraciones de nuestro pueblo no hubiera podido hacer hoy ante Vds. esta declaración.

Damos las gracias al Presidente Gorbachov, quien con su valerosa política ha abierto a Europa un nuevo futuro y ha brindado a Alemania la oportunidad de alcanzar su unidad en libertad. También esto va a marcar el futuro de las relaciones germano-soviéticas. Damos las gracias a los pueblos de Europa central y oriental. No olvidaremos nunca que el pueblo húngaro fue el primero que rasgó el telón de acero. Doy las gracias a mis colegas los Ministros de Relaciones Exteriores de los Estados Unidos de América, la Unión Soviética, Francia y el Reino Unido.

El mundo tiene la mirada puesta en Alemania. He aquí nuestro mensaje: sabemos cuál es nuestra responsabilidad y vamos a obrar en conformidad con ella.

Los alemanes no queremos sino vivir en libertad, en democracia y en paz con todos los pueblos de Europa y del mundo. 


\section{ALEMANIA. MAYOR RESPONSABILIDAD, NO MÁS PODER}

A nuestro juicio, la firma del documento final no supone únicamente la clarificación de los aspectos externos de la unificación alemana, lo cual de por sí ya constituye un acontecimiento histórico, un acontecimiento de alcance europeo. Entendemos asimismo que la firma de dicho documento brinda la oportunidad de comenzar, en términos globales, una nueva singladura en Europa.

Nosotros, la República Federal de Alemania, siempre hemos sostenido que la división de Alemania no podía superarse aisladamente, sino sólo dentro de un proceso paneuropeo. El mismo preámbulo de la Ley Fundamental vincula la unidad estatal de los alemanes a la integración europea y la salvaguardia de la paz mundial. En los Acuerdos de Bonn se fijaron las obligaciones de las tres potencias occidentales - los Estados Unidos de América, la República Francesa y el Reino Unido de Gran Bretaña e Irlanda del Norte- en orden al respaldo de la aspiración de la unidad alemana. La Carta sobre la unidad alemana incorporó al Tratado de Moscú nuestra meta de alcanzar la unidad estatal en un contexto europeo, pero también la convirtió en parte integrante del Tratado sobre las bases de las relaciones entre la República Federal de Alemania y la República Democrática Alemana. Finalmente, por lo que respecta a la preparación del Acta Final de Helsinki, insistimos en que se mantuviera abierta la opción alemana y europea. Merced a la integración de la República Federal de Alemania en la Comunidad Europea y en la Alianza Atlántica, la política alemana forjó las estructuras de estabilidad europeas y transatlánticas que eran posibles bajo las condiciones imperantes a la sazón, contribuyendo, a través del determinante papel desempeñado en la puesta en marcha y plasmación efectiva del proceso CSCE, a superar progresivamente los antagonismos en Europa y a hacer posible una nueva situación en Europa, situación que a la postre terminaría por facilitar asimismo la solución de la cuestión alemana.

Indudablemente, a lo largo de los difíciles años del antagonismo Este-Oeste la estabilidad de la Alianza Atlántica contribuyó de manera esencial a preservar la seguridad en Europa. Es igualmente indudable que gracias a la capital transformación de la política soviética los países europeos pudieron aprovechar las opciones que se planteaban a escala europea. Así fue posible la revolución en pos de la libertad en los países de Europa central y oriental. Así fue posible la revolución por la libertad en la RDA, y a partir de ahí se pudo cumplir también el deseo de los alemanes de alcanzar su unidad estatal. 
La política seguida por la República Federal de Alemania en lo tocante a la concertación de tratados, los Tratados de Moscú y de Varsovia, el Tratado concluido con la República Federal Checa y Eslovaca y el Tratado sobre las bases de las relaciones entre la República Federal de Alemania y la República Democrática Alemana fueron las premisas para la firma del Acta Final de Helsinki. Y ésta última a su vez dio paso a unos procesos en Europa que terminarian posibilitando a la par la política de Gorbachov.

Siempre hemos considerado que las relaciones germano-soviéticas constituyen un factor relevante y central para Europa. Ello se patentizó en la declaración germano-soviética del 13 de junio de 1989. Además, no dejamos de insistir en que durante los decisivos meses del viraje en Europa se fijarán, mediante la creación de nuevas estructuras europeas, unas condiciones marco estables en orden a los procesos de transformación en Europa en cuanto tal y dentro de los Estados de Europa central y oriental.

En el plano de las relaciones con la Unión Soviética se trataba de convencer a la cúpula soviética de que la unificación alemana no comportaría sino más ventajas también para la Unión Soviética. Se nos presentan grandes oportunidades de desarrollar, con la mirada puesta en el futuro, una amplia y extensa cooperación entre la Alemania unida y la Unión Soviética, una cooperación que acabamos de definir con todos los pormenores en el tratado firmado el pasado jueves. Esta cooperación no es sólo un acontecimiento a nivel bilateral, sino que asegura a la Unión Soviética una estrecha trabazón con los destinos de Europa, precisamente a través de esa estrecha cooperación con la República Federal de Alemania, que es un componente importante de la Comunidad Europea y de la Alianza Atlántica y un motor del proceso CSCE para Europa en su conjunto. El proceso CSCE brindará a la Unión Soviética la oportunidad de participar a nivel institucional en la construcción de Europa. Este punto constituyó uno de nuestros principales objetivos a la hora de articular la arquitectura de la cohesión alemana y europea. La participación de la Unión Soviética en la futura configuración de Europa es irrenunciable. Europa -en su conjunto- no puede materializarse contra la Unión Soviética ni tampoco sin la Unión Soviética, sino únicamente con el concurso de la Unión Soviética. Lo que está en juego es la Europa cabal. En cuanto alemanes, asumimos con especial empeño esta responsabilidad.

Ante este telón de fondo, nos congratulamos de que la República Francesa y la Unión Soviética estén manteniendo consultas sobre la concertación de un tratado que por su trascendencia equivale al que firmamos el 13 de septiembre en Moscú. Con ello se evidencia al mismo tiem- 
po que las políticas francesa y alemana tienen una perspectiva paralela en relación con el Este.

La declaración alemana de renuncia a las armas $A B C$ y la reducción de los efectivos militares a 370.000 hombres, lo que prácticamente supone una reducción de más del $40 \%$, ponen asimismo de manifiesto que la Alemania unida seguirá una política de predicar con el ejemplo, en la esperanza de que cunda. Somos plenamente conscientes de que la Alemania unificada tendrá mayor peso en Europa. También sabemos que los pueblos de Europa se plantean la pregunta de qué harán los alemanes con ese nuevo peso. La respuesta ha de ser clara y terminante: no pretendemos alcanzar un mayor poder a partir de ese nuevo peso; antes bien, estamos resueltos a afrontar una mayor responsabilidad. Mayor responsabilidad en orden a la configuración de las relaciones franco-alemanas, que -estamos convencidos de ello- tendrán aún mayor alcance precisamente después de la unificación alemana. $Y$ ya no sólo de cara a la construcción de la Comunidad Europea, sino con vistas al proceso paneuropeo.

Mayor responsabilidad significa asimismo fortalecimiento del proceso de integración de la Comunidad Europea en la senda hacia la Unión Europea. Unión Europea entendida como Unión Política, pero también como Unión Económica y Monetaria.

Mayor responsabilidad significa reconocer nuestro compromiso en relación con la evolución en Europa central y oriental. No queremos que Europa se vea dividida por un nuevo muro de diferencias sociales ahora que se ha demolido el muro de los antagonismos ideológicos y el muro de piedra; es decir, el desarrollo económico de Europa central y oriental debe encuadrarse en la óptica de la interdependencia. Mayor responsabilidad significa que vamos a propiciar con renovado empeño precisamente el desarrollo del proceso CSCE. Hemos reconocido a tiempo las grandes expectativas que atesora este proceso y vamos a seguir potenciándolo también en lo sucesivo. Mayor responsabilidad significa asimismo fortalecimiento de las relaciones transatlánticas. El Atlántico no debe ensancharse a medida que Europa vaya aglutinándose. 